\title{
A PRODUÇÃO DE BLOGS PROFISSIONAIS COMO FERRAMENTAS REFLEXIVAS NA EDUCAÇÃO INICIAL DE PROFESSORES DE LÍNGUA INGLESA
}

\author{
THE PRODUCTION OF PROFESSIONAL BLOGS AS REFLEXIVE TOOLS IN PRE-SERVICE \\ ENGLISH TEACHER EDUCATION
}

\author{
Lucas Moreira dos Anjos-Santos* \\ Monash University \\ Melbourne, VIC, AU \\ Vera Lúcia Lopes Cristovão* \\ Universidade Estadual de Londrina \\ Londrina, PR, BR
}

\begin{abstract}
Resumo
Nesse artigo, objetivamos analisar a produção de blogs profissionais de alunas-professoras e os papéis que tais práticas digitais de linguagem podem desempenhar na educação de professores de línguas reflexivos e críticos. Especificamente, analisamos as postagens de blogs que duas alunas-professoras produziram e as identidades profissionais que são forjadas a partir dessa prática digital de linguagem. O estudo relatado é qualitativo, interpretativista e se configura como um estudo de caso. Os dados, as postagens das alunas-professoras em seus blogs e relatos de experiência sobre a prática pedagógica que originou as postagens, foram gerados em $2010 \mathrm{em}$ uma disciplina optativa de um curso de Letras-Inglês de uma universidade estadual do norte do Paraná. Os resultados evidenciam a emergência de conflitos identitários por parte das alunas-professoras a partir de seu engajamento na produção de práticas digitais de linguagem. Esses conflitos se configuraram como um impulso para (re)constituição identitária dessas futuras profissionais da língua inglesa.
\end{abstract}

Palavras-chave: Blogs profissionais; Educação de professores de línguas; Tecnologias digitais; Identidades profissionais.

\begin{abstract}
In this paper, we aim to analyze the production of professional blogs by pre-service English teachers and the roles that such digital language practices may perform in the education of reflexive and critical language teachers. Specifically, we analyzed the blog posts that two pre-service teachers produced and the professional identities that are forged in such a digital language practice. The reported case study is of qualitative and interpretative nature. The data, composed by the pre-service English teachers' blog posts and their experiential narratives regarding the pedagogical practice they experienced, were generated in 2010 in an elective unit in a state university of the north of Paraná. The results demonstrate the emergence of identity conflicts due to the engagement of the pre-service English teachers in the production of digital language practices. These conflicts have generated an impulse towards the reconstruction of the identities of these future English language professionals.

Keywords: Professional blogs; Language teacher education; Digital technologies; Professional identities.
\end{abstract}

\footnotetext{
* Doutorando em Educação na Monash University, Melbourne, Austrália e bolsista da CAPES processo n. 0965120. Seus interesses de pesquisa se concentram no uso de tecnologias digitais para a aprendizagem de línguas e educação de professores e nos estudos de letramentos de cunho sociocultural, com enfoque principal em letramentos digitais e grupos sociais marginalizados. Email: lmanjos.santos@gmail.com

** Professora associada da Universidade Estadual de Londrina (UEL), membro do Programa de Pós-Graduação em Estudos da Linguagem (PPGEL-UEL) e líder do grupo de pesquisa Linguagem e Educação (desde 2002). Tem experiência na área de Linguística Aplicada, atuando principalmente nos seguintes temas: gêneros textuais, educação inicial e continuada de professores de línguas, ensino de língua estrangeira e estudos de produção textual. É bolsista de Produtividade em Pesquisa do CNPq desde março de 2013. Email: veraluciacristovao@gmail.com
} 


\section{Introdução}

A educação de professores de línguas adicionais tem apresentado nos últimos anos uma crescente produção de pesquisa enfocada nos usos, papéis, oportunidades e desafios que as tecnologias digitais de informação e comunicação apresentam às práticas educacionais vigentes (SANTOS, 2013). De nosso lado, desenvolvemos e implementamos uma experiência de educação de professores de línguas durante o ano de 2010 cujo objetivo era propiciar oportunidades significativas de engajamento com letramentos digitais por parte de alunas-professoras de um curso de Letras do norte do Paraná.

Baseando-nos na pesquisa que desenvolvemos em 2010, neste artigo objetivamos analisar a produção de blogs profissionais de alunas-professoras e os papéis que tais práticas digitais de linguagem podem desempenhar na educação de professores de línguas reflexivos e críticos. Especificamente, analisamos as postagens de blogs que duas alunas-professoras produziram e as identidades profissionais que são forjadas a partir dessa prática digital de linguagem.

$\mathrm{O}$ artigo encontra-se dividido em quatro partes. Nas duas primeiras partes, discutimos o conceito de blogs enquanto gênero digital e sua relevância para a educação de professores de línguas. Na terceira parte, detalhamos os aspectos metodológicos da pesquisa. Finalmente, apresentamos as análises e discutimos as implicações do engajamento das alunas-professoras com a prática digital de linguagem propiciada pelos blogs profissionais.

\section{Conceituando o blog profissional como um gênero digital}

Miller e Shepherd (2009) realizaram estudos sobre o blog como gênero e afirmaram que ele pode ser caracterizado como um gênero cujo objetivo é compartilhar assuntos de interesse comum em uma comunidade virtual imaginada. Os blogs são tanto relacionados à escrita sobre si quanto à escrita sobre assuntos que de alguma forma geram adesão da sociedade. Como apontam os autores (2009, p. 75) “(o) que a maioria dos blogueiros acha mais atraente nos blogs é a habilidade de combi- nar o imediatamente real e o genuinamente pessoal". De certa forma, o blogueiro é sua própria audiência. É uma escrita de si para si mesmo. E é exatamente esse caráter autorreflexivo que justificaria o seu uso na educação de professores.

Miller e Shepherd (2009) entendem que o blog surge dentro de um contexto histórico em que as fronteiras entre o público e o privado têm se apagado. Além disso, aquilo que consideramos mundo real passa a ser constituído por um mundo virtual, um simulacro em que o virtual passa a ser real. Os blogs surgem, originalmente, como uma forma de compartilhar interesses e a maioria dos blogueiros concorda que o mais importante nessa prática de linguagem é seu conteúdo. A própria organização do gênero $b \log$, em forma inversamente cronológica, imprime a sensação de proximidade com seu interlocutor.

Diante disso, Miller e Shepherd (2009, p. 91) reiteram que os blogs servem como ferramentas de consolidação e validação do self, como uma resposta a um momento sociocultural de desestabilização das identidades dos indivíduos. Como defendem os estudiosos, “o blog deve ser compreendido como uma reação particular ao constante fluxo de subjetividade, como uma tentativa genérica de reflexão dentro do sujeito que cria um redemoinho de relativa estabilidade".

Esse primeiro estudo dos autores sobre o blogé posteriormente reconsiderado em um texto sobre as questões da blogosfera em que argumentam que o blog não é um gênero e sim um meio (MILLER; SHEPHERD, 2009). Para sustentar esta nova posição, os autores reexaminam o blog pessoal. De acordo com eles, o blog pessoal passou por três fases distintas: a) em um primeiro momento era usado por programadores que conheciam as linguagens de codificação para buscar links na internet e torná-los disponíveis com comentários; b) posteriormente houve a criação de interfaces tecnológicas que permitiram ao usuário que não possui conhecimentos técnicos também fazer uso do blog para postar assuntos de seu interesse; e por fim c) há uma mudança na maneira pela qual os leitores acessam as entradas dos blogs, bem como sua proximidade e relações com demais redes sociais de promoção pessoal. Nesse sentido, 
Os traços formais dos blogs evoluíram lentamente através dessas três fases. Os blogs ainda são identificáveis pela composição das entradas estampadas com dia e hora, organizadas na ordem cronológica inversa, e a maioria também inclui um link para os comentários do leitor e o nome do autor. A cronologia inversa e o hábito de colocar dia e hora nas postagens criam uma 'expectativa de atualizações' (Hourihan, 2002) e assim uma motivação para os leitores retornarem ao blog. O uso do tempo presente nas postagens datadas cria uma imediação semântica, como nos diários. (MILLER; SHEPHERD, 2009, p. 99).

A terceira fase dos blogs também foi marcada pela mudança radical no papel do usuário da internet. $\mathrm{O}$ internauta tem a possibilidade não só de acessar o conteúdo online como também pode produzir e disponibilizar suas criações para um público potencialmente de amplo alcance. A partir desse cenário, Miller e Shepherd (2009) passam a analisar os blogs que se especificaram em conteúdo jornalístico e político (ou blog público) e a variedade de usos que são feitos desse gênero no decorrer da década de 2000.

O surgimento do blog público se deve, em parte, ao crescente ceticismo em relação à mídia convencional altamente estratificada e controlada por grandes grupos empresariais do setor de comunicações e, em parte, à sensação de realidade quando eventos de impacto mundial, como o 11 de setembro, são relatados por civis que vivenciaram de perto tais acontecimentos. Assim sendo, "[...] os blogs fornecem maneiras de se engajar nos assuntos, de participar em discussões, de rebaixar/ diminuir/sabotar a homogeneidade da mídia corporativa e de converter as audiências em comunidades participativas" (MILLER; SHEPHERD, 2009, p. 112).

A partir dessas considerações sobre os blogs pessoais e públicos é que os pesquisadores analisam o papel do meio na constituição desse gênero. Para tanto, eles lançam mão do conceito de affordances, que seriam as funcionalidades ou características que permitem a determinado meio possibilitar ou dificultar determinadas práticas linguageiras e não outras, bem como acentuar suas propriedades. Como exemplos de affordances da internet são citados os hiperlinks, a conectividade, a indexação, os mecanismos de busca, a interatividade, entre outros. Tendo por base tal conceito, os autores postulam que as affordances do meio não são fatores determinantes na constituição de um novo gênero, mas são, na verdade, integrados à própria necessidade social gerada num dado momento sociocultural. Nesse sentido, "parece claro que o blog é uma tecnologia, um meio, uma constelação de affordances - e não um gênero" (MILLER; SHEPHERD, 2009, p. 117).

Sob outro viés, Pereira (2007) também afirma que o blog não é gênero. Para a autora, a partir de uma análise desenvolvida por meio da observação de diferentes exemplares do gênero em questão, o blog pode ser considerado como um suporte para diferentes gêneros discursivos. O blog se assemelharia ao jornal que congrega diferentes gêneros na forma de um portador. A autora baseia-se nas definições de gênero de Marcuschi (2004) ao ressaltar a natureza sociocomunicativa dessas ferramentas.

De nosso lado, discordamos, ao menos em parte, das compreensões que veem o blog somente como suporte ou como um meio. Assim como defendemos que o fórum seja tanto um meio quanto um gênero (ANJOS-SANTOS; CRISTOVÃO, 2013), acreditamos que os blogs sejam ferramentas semióticas culturais cuja ação social é singular. Partindo do conceito de affordances, como apresentado por Miller e Shepherd (2009), entendemos as funcionalidades e características típicas do blog como sendo parte da tipificação social produzida pelo uso recorrente de tal gênero.

Dessa forma, o blog, enquanto gênero, permite uma reorganização de propósitos discursivos de outros gêneros e integra-os na realização de seu projeto enunciativo. Assim, quando um agente-produtor disponibiliza uma notícia televisiva em seu blog e tece comentários a respeito, a função sociocomunicativa da notícia televisiva passa a ser subordinada à função sociocomunicativa do blog. A ação social pretendida pelo agente-produtor é de compartilhar determinada notícia e buscar adesão, na comunidade virtual da qual faz parte, acerca do projeto discursivo disponibilizado.

Ainda consideramos ser produtivo, a partir da noção de constelação defendida por Araújo (2006), entender um blog como uma tecnologia da web em que diferentes gêneros se constelam ao seu redor. O blog pes- 
soal, o blog público, o blog jornalístico, o blog humorístico, dentre outros. Portanto, nessa pesquisa, adotamos o blog tanto como um meio quanto um gênero. $\mathrm{O} b \log$ produzido pelas alunas-professoras, em nossa pesquisa, se configurou como um blog profissional cuja ação de linguagem requerida era refletir e posicionar-se diante de temas da esfera profissional da qual participam, de modo a conseguir adesão social às causas defendidas.

Assim, a ação de linguagem prototípica do blog profissional se configura da seguinte forma: um agente-produtor, no papel social de membro de determinada comunidade profissional, estabelece um diálogo com seus pares ou mesmo pessoas de outras áreas acerca de determinado assunto. O tema é potencialmente polêmico ou controverso de modo que o projeto enunciativo do agente-produtor requer, necessariamente, a busca de adesão de seus interlocutores, conforme ilustra o esquema da figura 1 .
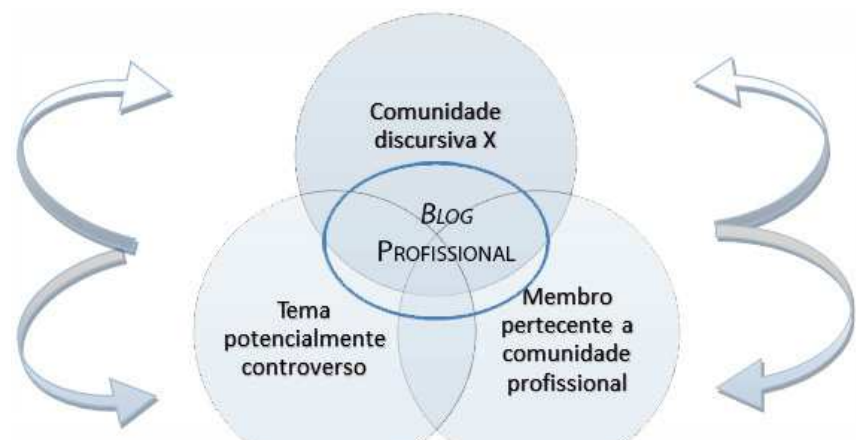

Figura 1 - Projeto enunciativo do gênero blog profissional

\section{O uso de blogs na educação de professores de línguas como ferramentas de (re)construção identitária}

No que tange ao uso de blogs em intervenções para educação de professores, Wassel e Crouch (2008) os utilizaram para integrar tecnologias digitais e educação multicultural em um curso de formação de professores para certificação inicial para educação básica. ${ }^{1}$ Os alunos-professores tinham como tarefa ler as postagens feitas pelos professores do curso, navegar pelos links sugeridos e elaborar uma resposta para comentar o referido tópico. Em relação aos resultados alcançados, os autores evidenciam: a) o papel do blog no desenvolvi- mento de pensamento crítico sobre questões da educação multicultural por parte dos alunos-professores; b) o projeto com o blog deu mais voz aos alunos, principalmente aqueles que não se sentiam confiantes o suficiente para se posicionar nas discussões de sala de aula; c) o uso de tecnologia baseada na web possibilitou que os alunos-professores desenvolvessem capacidades de uso e adaptação com tecnologias digitais e pudessem futuramente usá-los com seus alunos.

Analogamente, Reis (2009) ao analisar o uso das tecnologias no Colégio Militar de Fortaleza defende ser possível integrá-las à prática pedagógica do professor para promover situações de letramento digital. Nesse sentido, o uso do blog com fins pedagógicos pode oportunizar “(...) infinitas possibilidades para o desenvolvimento da escrita, da capacidade argumentativa, da criatividade, da organização, da estética, proporciona experiência de aprendizagem colaborativa e permite a reflexão sobre valores éticos" (REIS, 2009, p. 106). A autora acredita que a informática pode ter um papel preponderante na melhoria das práticas de ensino a partir de seu relato sobre o uso de blogs e e-mails já que enfatizam características como: autonomia, atividades de cunho interdisciplinar, aprendizagem colaborativa, entre outras.

Dadas essas características do gênero digital $b \log$, que relações podemos estabelecer entre ele e educação de professores? Acreditamos que a apropriação do gênero digital blog profissional pode desencadear momentos de (re)construção identitária para o aluno-professor em educação inicial. Tal papel pode ainda ser acentuado se levarmos em conta que a produção linguageira é espaço de embate de vozes em que múltiplos sentidos e significados são constantemente negociados.

A argumentação, por meio do blog, pode gerar um confronto de vozes que constituem o indivíduo e induzem a problematizações sobre seu self. É por meio do saber-dizer propiciado pelo blog que pode se dar a inscrição do indivíduo em papéis em que ele pode se ver ou não como profissional da linguagem (MATENCIO, 2008).

\section{Metodologia}

A pesquisa relatada neste artigo é de cunho qualitativo e interpretativista. De acordo com Cohen, 
Manion e Morrison (2007), a pesquisa qualitativa de cunho interpretativista tem por objetivo compreender os significados que indivíduos socialmente situados constróem em relação às atividades nas quais engajam e a subjetividade da experiência humana. A pesquisa se configura como um estudo de caso, que é uma instância específica destinada a ilustrar um princípio de cunho mais geral. Os estudos de caso caracterizam-se pelo olhar analítico e profundo de uma situação específica, envolvimento do pesquisador, percepção dos participantes sobre a situação enfocada, detalhamento rico e profundo da situação pesquisada (COHEN; MANION; MORRISON, 2007).

A geração de dados ocorreu durante o primeiro semestre de 2010 na disciplina optativa Gêneros textuais e Ensino de Línguas Estrangeiras, ofertada para alunos- professores ${ }^{2}$ do terceiro ano do curso de Letras Estrangeiras Modernas de uma universidade pública estadual. A disciplina contou com a participação de quatro alunas-professoras que concordaram em também participar da pesquisa por meio da cessão de seus textos e relatos de experiência produzidos ao longo das aulas.

Durante o ano de 2010, as alunas-professoras se engajaram na produção e leitura de artigos de opiniões, fóruns de discussão educacional, blogs profissionais e chats educacionais além de discutirem as teorias subjacentes às atividades pedagógicas nas quais se engajavam. As concepções teóricas e metodológicas que fundamentaram a prática pedagógica dos formadores eram baseadas em uma abordagem com base em gêneros (CRISTOVÃO, 2009).

Em relação aos instrumentos de geração de dados, todas as postagens produzidas pelas alunas-professoras em seus blogs foram coletadas. Para produção do blog, usamos o site <www.blogger.com> em função de ser um dos mais conhecidos para criação de blogs e de fácil acesso. Ao final da experiência com a produção de blogs, as alunas-professoras também produziram um relato de experiência, narrando e problematizando sua vivência com o gênero digital em foco. Ao contrário das postagens em seus blogs que eram textos públicos, os relatos de experiência foram produzidos unicamente como dados de pesquisa e não foram publicados.
As participantes da pesquisa foram quatro alunas-professoras: Taylor, Joana, Libela e Ma. ${ }^{3}$ Por questões de espaço, selecionamos, neste artigo, as postagens e os relatos de duas alunas-professoras: Taylor e Joana. A escolha de ambas se justifica na medida em que elas não tinham interesse em se tornar professoras de inglês e, portanto, vivenciaram mais conflitos com a prática pedagógica implementada cujo foco principal era a formação profissional dessas alunas. O Quadro 1 apresenta o perfil descrito no início do ano letivo por meio de conversas informais com as alunas-professoras.

Quadro 1 - Perfil das alunas-professoras foco neste artigo

\begin{tabular}{|l|l|l|}
\hline Aluna-professora & Idade & Aspirações profissionais \\
\hline Joana & 21 & $\begin{array}{l}\text { Não deseja ser professora } \\
\text { de inglês. Possui fascínio } \\
\text { pela aprendizagem de } \\
\text { inglês. }\end{array}$ \\
\hline Taylor & 21 & $\begin{array}{l}\text { Não tem interesse em ser } \\
\text { professora. Quer trabalhar } \\
\text { com tradução. }\end{array}$ \\
\hline
\end{tabular}

As análises foram desenvolvidas tendo por base o modelo de análise textual-discursiva de Bronckart (2003), categorias da Semântica Argumentativa (KOCH, 1997) e categorias provenientes da revisão de literatura previamente apresentada. O modelo de análise textual-discursiva de Bronckart (2003), num primeiro momento, é ancorado sob o ângulo do contexto de produção, macro e micro. Em nível micro, é feito um levantamento do contexto de produção da situação linguageira do texto em análise com base nos parâmetros físicos e sociosubjetivos apresentados por Bronckart (2003).

Quadro 2 - Parâmetros do contexto de produção de textos

\begin{tabular}{|c|c|c|}
\hline \multirow[b]{2}{*}{ 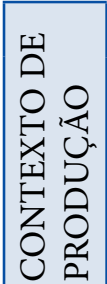 } & Parâmetı & Parâmetros sociosubjetivos \\
\hline & $\begin{array}{l}\text { Lugar de produção } \\
\text { Momento de } \\
\text { produção } \\
\text { Emissor } \\
\text { Receptor }\end{array}$ & $\begin{array}{l}\text { Lugar social } \\
\text { Posição social do emissor } \\
\text { Posição social do destina- } \\
\text { tário } \\
\text { Objetivo da interação }\end{array}$ \\
\hline
\end{tabular}


O próximo nível de análise incide sobre a arquitetura interna dos textos. O plano textual global se refere à "organização de conjunto do conteúdo temático; mostra-se visível no processo de leitura e pode ser codificado em um resumo" (BRONCKART, 2003, p. 120). Os tipos de discurso são identificados a partir de características linguísticas específicas mobilizadas numa determinada língua natural e surgem do cruzamento entre as coordenadas do mundo do narrar e do mundo do expor com relação ao ato de produção da ação linguageira. De acordo com Bronckart (2003), os tipos de discurso são:

Quadro 3 - Tipos de Discurso conforme Bronckart (2003, p. 157)

\begin{tabular}{|c|c|c|c|}
\hline & \multicolumn{3}{|c|}{ Coordenadas Gerais dos Mundos } \\
\hline \multirow{3}{*}{ 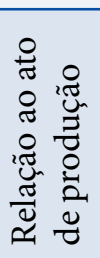 } & & $\begin{array}{l}\text { Conjunção } \\
\text { EXPOR }\end{array}$ & $\begin{array}{l}\text { Disjunção } \\
\text { NARRAR }\end{array}$ \\
\hline & Implicação & INTERATIVO & $\begin{array}{l}\text { RELATO } \\
\text { INTERATIVO }\end{array}$ \\
\hline & Autonomia & TEÓRICO & NARRAÇÃO \\
\hline
\end{tabular}

As sequências são "modos de planificação de linguagem, que se desenvolvem no interior do plano geral de texto" (BRONCKART, 2003, p. 121). Ancorado nos estudos de Adam (1991, apud BRONCKART, 2003), o autor apresenta cinco sequências: a narrativa, a descritiva, a argumentativa, a explicativa e dialogal.

Finalmente, nossa análise incide sobre os mecanismos enunciativos que contemplam modalizações e vozes. As modalizações podem ser divididas em: lógicas, que avaliam o conteúdo mobilizado do ponto de vista das condições de verdade; deônticas, que avaliam o conteúdo mobilizado do ponto de vista das condições sociais e institucionais; apreciativas, que avaliam o conteúdo mobilizado do ponto de vista das condições subjetivas e de julgamento; e as pragmáticas, que avaliam o conteúdo mobilizado do ponto de vista da responsabilização/agentivização do produtor.

Os actantes postos em cena nos textos produzidos, por meio de pronomes, sintagmas nominais e anáforas pronominais, revelam-nos a posição enunciativa do agente-produtor e sua responsabilidade sobre o que está sendo dito. Além do mais, a progressão dessas marcas de pessoa nos permite analisar o movimento do papel social assumido pelo agente-produtor (MACHADO; BRONCKART, 2009). Para identificação dos papéis assumidos e atribuídos às alunas-professoras, realizamos o levantamento das marcas de pessoas por meio de dêiticos pessoais e dos movimentos argumentativos por meio dos operadores, além do uso das modalizações.

Da Semântica Argumentativa, utilizamos a concepção de argumentação presente nas produções linguageiras e o papel dos operadores argumentativos na construção argumentativa com base em Koch (1997).

\section{Análise e discussão dos dados}

Em relação ao engajamento de Taylor no blog, sete postagens foram produzidas variando entre o uso da sequência argumentativa e explicativa. Nas postagens de Taylor, a posição mais recorrente, assumida pela aluna-professora, é a de membro externo à comunidade profissional na qual se encontra. A aluna-professora só se assume enquanto tal em duas postagens. Nas demais, ela textualiza suas postagens a partir de uma posição enunciativa distante e teórica, conforme a seguir.

\section{Excerto 1 - Terceira Postagem de Taylor no Blog}

But I do agree that this matter of globalization has been rooted in our learning practice in such a way that interferes in our personality, habits, culture, etc. So that the matter of power is implicit when learning a language. Despite of this, learning foreign languages is a matter of inclusion. It's kind of... being part of the "whole thing". It enables you to participate in discussions in an active way, to point your opinions out, to stand for yourself, to know people...It enables you to be critical in the world, with an active voice and a possibility of being recognized and being listened by people from all over the world. Taylor.

O excerto 1 ilustra a posição recorrente de Taylor que se projeta distante do que está sendo dito. Ela se implica por meio do dêitico pessoal I (But I do agree that this matter of globalization has been rooted in our learning practice in such a way, that interferes in our personality, habits, culture, etc ...) para marcar que essa é sua opinião e a enfatiza por meio do uso do auxiliar do. A aluna-professora também se implica, ainda que de forma generalizante, por meio do uso do dêitico pessoal our. Seu uso 
refere-se a ela e outros aprendizes de língua (our learning practice, our personality) como sendo influenciados pelo papel da língua inglesa na globalização. Na sequência, são empregadas diversas orações no discurso teórico (So that the matter of power is implicit when learning a language) para argumentar a favor do ponto de vista defendido: aprender uma língua estrangeira é engajar-se criticamente num mundo globalizado. A imagem que a agente-produtora quer passar ao seu interlocutor é ressaltada pelo uso de itens lexicais que denotam representações positivas sobre o papel de uma LE na formação do indivíduo de forma geral (participate in discussion, active way, be critical, active voice, being recognized).

A posição enunciativa, assumida por Taylor nesse tipo de postagem, é a de apropriar-se das palavras alheias e torná-las suas no intuito de construir uma argumentação mais sustentada. Taylor sai de cena e evidencia como protagonista de seu discurso a própria língua inglesa. $\mathrm{O}$ discurso de Taylor é construído de maneira monologada e assumido como uma verdade inquestionável. Tal uso coaduna-se ao próprio excerto ao qual Taylor reage: um trecho de um artigo acadêmico. Em vista disso, acreditamos que a resposta da aluna-professora procurou se adequar ao(s) discurso(s) que ecoava, mesmo que essa fosse sua opinião.

É importante salientar as contradições presentes no dizer de Taylor quando de sua participação no blog. Uma das mais salientes é no momento em que a aluna-professora se marca enunciativamente como professora e logo em seguida se contradiz. Essa postagem, excerto 2, requeria que as alunas-professoras realmente pensassem como se viam como professoras.

\section{Excerto 2 - Sexta Postagem de Taylor no Blog}

\section{Who are you as a teacher?}

So, while I was wondering about that, I realized I don't really know who I am as a teacher. I think I haven't completed my profile yet. And I still have a lot to learn about being a teacher, and really making the difference and changing something in the students lives. When I started teaching, I had a pessimistic vision of all this, and I really though we couldn't change that much. But now I'm starting to think of my own practice and other's practices as well, and I kind of saw that we can change something, even if it's a tiny something, and just in one, ore maybe two students... it doesn't matter. We changed.
I think that first of all I myself need to be hopeful and full of joy to go everyday to work. It is obviously hard, I know, but if I've decided to do that, then I need to value this and make it become worthy. Teacher should always have an open mind, so that they could have a way to make some dream come true. I really admire the ones that say: I want to be a teacher for the rest of my life. You know, this ones look like they were born for it, as if they have been given a special commission. I'm not one of this, but I say good luck for them. They gotta be really courageous and full of strength for that. But at the end of each day I do think they have this feeling of something accomplished, of peace and being released. That's it.

Taylor.

Na primeira parte da postagem, Taylor faz uso do discurso relato interativo para contar como se vê como professora e relatar sua experiência como estagiária do PIBID (When I started teaching, I had a pessimistic vision of all this, and I really though we couldn't change that much). A aluna-professora marca sua posição de dubiedade quanto ao fato de ser professora por meio do uso dos operadores argumentativos yet e still. Ela também faz uso de modalizações lógicas e do passado para demonstrar que, anteriormente ao curso, ela acreditava ser impossível mudar a realidade escolar (... and I really though we couldn't change that much). No entanto, suas representações são reconstruídas a partir de sua vivência no curso e ela passa a empregar uma apreciação valorativa da ordem do possível em relação ao papel dos professores, novamente marcado pelo uso da modalização lógica, do tempo presente e do operador argumentativo adversativo (But now I'm starting to think of my own practice and other's practices as well, and I kind of saw that we can change something).

Na segunda parte da postagem, Taylor ancora sua posição a partir do discurso teórico e passa a falar de professores de um modo genérico (Teacher should always have an open mind, so that they could have a way to make some dream come true). Desde então, a alunaprofessora, que anteriormente relatava sua mudança de percepção em relação a ser professor, passa a projetarse enunciativamente como alguém que não deseja ser essa profissional. Para se diferenciar dos professores de "verdade", Taylor faz uso do discurso direto para reproduzir os entendimentos delas sobre a profissão e da modalização lógica para colocar isso sob condições 
de verdade (I really admire the ones that say: I want to be a teacher for the rest of my life). A aluna-professora continua sua postagem por meio do uso de ironia para deixar marcado que não faz parte do rol de pessoas que desejam ser professores (I'm not one of this, but I say good luck for them.).

Considerando o exposto, salientamos que o processo de apropriação do gênero digital blog parece ter propiciado um espaço para reflexão da aluna-professora sobre o processo de (re)constituição identitária profissional deflagrado pela sua participação no curso de Letras. Se recuperarmos a ideia de que a argumentação, por meio do blog, pode gerar um confronto de vozes que constituem o indivíduo e induzir a problematizações sobre seu self, essa postagem de Taylor evidencia o conflito vivenciado pela aluna-professora em relação ao curso, sua participação no PIBID e em relação a sua participação na disciplina em foco.

Taylor marca enunciativamente em seu relato de experiência a distância entre os objetivos almejados pelos professores da disciplina e a posição da aluna-professora sobre a adoção do gênero blog como um instrumento de mediação formativa. É importante notar que em função de sabermos a opinião da aluna-professora durante a pilotagem da sequência didática, ela inicia a textualização de seu relato com a seguinte afirmação: "Everybody knows my opinion about that". O uso do pronome indefindo everybody refere-se aos demais participantes (professores e alunas) da disciplina que tiveram a oportunidade de conhecer e debater sobre o uso de blogs. A aluna-professora coloca sua opinião e a razão no seguinte trecho:

Excerto 3 - Relato de experiência sobre a SD de blog de Taylor

I still keep the opinion that blogs were made for another purpose: to talk about people's day by day life and experiences. So, if we want to use that another purpose (for teachers to talk about their practices, about ways to teach or theoretical things) why not use another genre that fits better in this specific situation? I mean, a genre that was made for that goal! (Taylor, linhas 2-6) sociais e, portanto, contempla a ação social comunicativa que o gênero blog enquanto instrumento permite ao indivíduo realizar. As representações de Taylor acerca do propósito comunicativo do blog (to talk about people's day by day life and experiences) não são desestabilizadas ou (re)construídas a partir do engajamento da aluna-professora com a aprendizagem de capacidades de linguagem referentes ao gênero blog. Isso é evidenciado, principalmente, pelo uso do advérbio still indicando um estado de permanência de opinião por parte da aluna-professora mesmo depois da intervenção (I still keep the opinion...).

O propósito comunicativo subjacente ao uso do blog profissional (for teachers to talk about their practices, about ways to teach or theoretical things) não funcionou como base de orientação enunciativa para deflagrar a participação de Taylor em sua (futura) comunidade profissional.

Esse excerto ainda revela o processo de (re)construção de saberes profissionais por parte de Taylor quando a aluna-professora se engaja numa meta-reflexão sobre o uso do instrumento blog. Discordar da adequação da escolha do gênero como instrumento formativo para educação de professores permite que Taylor, e os demais participantes da disciplina, possam discutir os critérios de seleção e adoção de gêneros para o ensino e a aprendizagem de línguas. Por conseguinte, o uso de uma forma de TDIC possibilitou aos alunos-professores desenvolverem capacidades de uso e adaptação com as mesmas para outros contextos (WASSEL; CROUCH, 2008).

A participação de Taylor no blog ainda desencadeou um processo de reflexão das representações da aluna-professora sobre o papel do professor. O excerto a seguir ilustra esse momento que também é uma sequência do desenvolvimento do argumento de Taylor sobre a inadequação do uso do blog como instrumento formativo (dessa vez, o foco da aluna-professora não mais é em seu próprio processo formativo, mas no dos aprendizes de línguas da educação básica).
O foco da argumentação de Taylor em relação à discordância do uso do blog recai sobre as exigências 
Excerto 4 - Relato de experiência sobre a SD de blog de Taylor

Anyway, I don't like this new things even though I know I have to get used to that. But for me, these are not serious things...It's another world, in which I don't belong, and for it's no real as well. We should take real things into classroom, to real students. We shouldn't be encouraging them to live this surreal world, instead, we our role should be to keep their foot on the ground, always presenting the reality. (Taylor, linhas 6-10)

O excerto inicia-se com o uso do discurso interativo para marcar a posição de Taylor em relação às tecnologias digitais de um modo geral (e ao blog, especificamente nesse caso): a aluna-professora se implica por meio do pronome pessoal $I$, para expressar seus sentimentos, ou sua valoração apreciativa subjetiva, em relação às tecnologias (Anyway, I don't like this new things...) e, em seguida, faz uso do operador argumentativo de oposição even though e da modalização lógica have to para marcar que, independentemente de seus sentimentos, lidar com tecnologias digitais é algo tido como da ordem das condições de verdade atualmente (even though I know I have to get used to that).

A posição de Taylor é recorrente, pois a relação estabelecida pela aluna-professora entre uso de TDIC e obrigatoriedade/coerção social (tida como uma verdade absoluta a ser seguida) já apareceu quando do seu relato da participação com o fórum de discussão educacional (ANJOS-SANTOS, 2014). Essa representação de Taylor sobre as TDIC parece ser parte de uma ideologia dominante (dentre tantas outras em constante embate na nossa sociedade) de que as TDIC são ferramentas imprescindíveis para qualquer pessoa que viva no século XXI. Essa lógica, na verdade, parece ser muito mais sustentada pelos mercados econômicos, de produção e de consumo de bens, do que pela real necessidade que as pessoas teriam de usar tais ferramentas ou não.

Ao retomarmos a posição de Taylor em relação ao uso do $b l o g$, percebemos que a aluna-professora, depois de expressar sua opinião em relação à ferramenta, passa a desqualificá-lo. Para tanto, ela constrói sua argumentação com base em duas posições: coisas reais e importantes versus coisas surreais e desnecessárias. Num primeiro momento, Taylor se implica por meio do uso do pronome objeto me para dizer que o blog e as TDIC de forma geral não são coisas reais (But for me, these are not serious things...). A seguir, Taylor expressa o que professores de línguas deveriam fazer, por meio do uso da modalização deôntica should, algo tido como da obrigatoriedade social, e incluindo ela mesma ao marcar por meio de um pronome pessoal plural we e do possessivo our. (We should take real things into classroom, to real students. We shouldn't be encouraging them to live in this surreal world, instead our role should be to keep their foot on the ground, always presenting the reality).

Fica claro nesse excerto a discordância de Taylor em relação ao uso de TDIC em sala de aula. É relevante notar ainda que a concepção de Taylor de realidade versus virtual é construída a partir de noções que compreendem esses conceitos como opostos. Na verdade, o virtual também é constitutivo daquilo que se convencionou chamar de real, como bem apontou Lévy (1999). Taylor não vê as TDIC como ferramentas que podem oportunizar um espaço de debate de diferentes posições perante o mundo (BRAGA, 2010) bem como engajar os alunos em situações reais de comunicação por meio da língua ensinada.

A posição antagônica de Taylor em relação ao uso do blog enquanto instrumento formativo bem como as possibilidades criadas a partir de seu engajamento na produção de seu próprio blog evidenciam o papel que o gênero blog pode ter como desencadeador de representações já cristalizadas.

Concernente às postagens de Joana no blog, a aluna-professora teve sete postagens predominantemente planificadas com a sequência argumentativa. As postagens de Joana no gênero blog se caracterizam pelo seu caráter altamente argumentativo, já que a aluna-professora compreendeu este espaço como um lugar de debates de opiniões. Ainda que ela se implique em todas as postagens, ela não se marca, frequentemente, como aluna-professora. Ela se projeta como aprendiz de língua, na grande maioria das postagens, conforme observamos no excerto 5 : 
Excerto 5 - Terceira Postagem de Joana no Blog

[...] I support the idea that the first reason-learning a FL
for economic purposes -is the one that motivates people
most. [...]
I think the only people who do not ONLY have the
economical reason for learning a FL is us- students
of English at the university, in Letras course. What
happened to us, I think, is that we feel in love with
English from the moment we met him. Because of this, we
wanted to go deep into this idea of "teaching and learning
English". We were fallen apart from the rest of the
citizens who look at English from a different perspective.
And you know what: we came to this graduation course
not because we wanted to learn English in order for
personal development. As I said above, we came here to
study English because we loved it - whenever I say we,
please, translate it as I. Human development and critical
practices were a consequence of it.

Joana se marca na postagem de duas maneiras: a) por meio do uso do dêitico pessoal I (I support the Idea that the first reason...) para marcar seu ponto de vista; b) por meio do uso do dêitico pessoal we e us (What happened to us, I think, is that we feel in love with English from the moment we met him.) para se referir aos alunos do curso de Letras, assim como ela. Ela inclusive marca linguisticamente na postagem que quando fala we também está se incluindo nesse grupo (...whenever I say we, please, translate it as I.). Ao se referir aos alunos de Letras, Joana faz uso de um aposto para esclarecer a quem está se referindo (...for learning a FL is us- students of English at the university, in Letras course).

A posição enunciativa de Joana, nesse excerto, revela as representações que a aluna-professora tinha sobre o curso de Letras, o que influencia diretamente a maneira como ela se vê. Conforme demonstrado anteriormente, ela se coloca, antes de qualquer coisa, como aprendiz de língua inglesa e sua paixão como primordial para sua escolha. Nesse sentido, Joana se apropria do blog e o (res)significa diferentemente do propósito almejado pelos professores da disciplina. Para a aluna, o blog é um espaço de aprendizagem da língua, de conhecer mais sobre a língua, de poder usar a língua efetivamente em situações reais de comunicação.

Joana se projeta como aluna-professora no blog quando relata sua experiência de estágio. Essa carac- terística parece indicar que a aluna-professora toma consciência de que, além de aprendiz de LI, também é futura profissional dessa área a partir de seu saber dizer sobre o saber fazer instaurado pelo estágio ${ }^{4}$ (MATÊNCIO, 2008). No excerto 6, Joana implica a si mesma e sua supervisora de estágio por meio do uso de dêiticos pessoais we e us (So before really start teaching students we came to the conclusion that we should know who we are dealing with... By getting to know them it would be easier for us to develop activities).

\section{Excerto 6 - Quarta Postagem de Joana no Blog}

What happened was that Marcia [supervisora de estágio] and $I$ are teaching the same class at this school (me as the internship which is part of my curriculum in college and her as data for her master's dissertation - since she is taking her master degree). So before really start teaching students we came to the conclusion that we should know who we are dealing with, that is, who these students are, where they come from, what they like, etc. By getting to know them it would be easier for us to develop activities that make sense for them and also we would become familiar with them and that is primarily important for us to develop a good relationship with students. So based on all this reflexion I came up with a simple questionnaire that would fulfill our expectations on what we would like to know from students.

Ainda nesse mesmo trecho, Joana avalia suas ações e de sua supervisora por meio do uso de modalizações lógicas. Isso indica uma provável articulação da aluna-professora entre a teoria, estudada na universidade, e os aspectos práticos, vivenciados no estágio. Dando prosseguimento, Joana ainda constrói representações sobre um dos papéis do professor (that is primarly important for us to develop a good relationship with students) por meio do uso de uma modalização apreciativa demonstrando o caráter subjetivo da (res)significação do que é ser professora por parte dela.

A constituição identitária de Joana, enquanto profissional, se dá na relação eu-tu-nós. É a partir de seu engajamento em práticas sociais comuns ao campo profissional do qual está participando que a aluna-professora repensa suas próprias concepções sobre a profissão. A participação no blog se configura como mais um desses espaços em que ela, por meio de um saber dizer, materializa suas representações de como se 
vê e tem a oportunidade de expressar seu self (MILLER; SHEPPERD, 2009; MATÊNCIO, 2008).

Em seu relato sobre sua participação no blog, Joana reconhece a importância que o gênero pode ter na aprendizagem de línguas, mas se distancia de fazer o uso de tal ferramenta, conforme podemos observar no excerto seguinte.

Excerto 7- Relato de experiência sobre a SD de blog de Joana

This genre is quite nice to deal with. Although I myself am not a huge fan of blogs - I didn't have one and probably won't continue using it for personal reason - I totally agree with the fact that this is a highly important tool for teaching English! (Joana, linhas 1-3).

Joana aprecia valorativamente sua interação com o gênero blog de maneira positiva ao fazer uso da locução adjetiva quite nice. Contudo, na sequência do excerto, a aluna-professora faz uso do operador argumentativo although e contrapõe sua apreciação positiva do gênero com o fato de que ele não será parte de seu dia-a-dia, por meio de uma modalização pragmática (and probably won't continue using it for personal reason). Esse excerto revela que as exigências sociais da ação tipificada possibilitada pelo blog não parecem ir ao encontro das motivações de Joana para continuar fazendo uso do gênero em outros contextos. Contraditoriamente, a aluna-professora avalia, por meio de uma modalização apreciativa, o blog como um instrumento adequado para o ensino e aprendizagem de língua inglesa (a highly important tool for teaching English!).

As representações de Joana sobre o gênero digital blog parecem indicar que a aluna-professora vê potencialidade em seu uso quando se trata de transpô-lo didaticamente para sua prática pedagógica de ensino de línguas, mas não o reconhece como um instrumento formativo profissional.

A reconcepção de Joana do motivo pelo qual estaria tendo contato com TDIC fica ainda mais evidente quando observamos o excerto a seguir em que a aluna-professora exemplifica como usar o blog como um instrumento pedagógico para o ensino de línguas e justifica sua afirmação.
Excerto 8 - Relato de experiência sobre a SD de blog de Joana

For instance, when I have my students I can post things in a blog and ask them to do a task as homework. We teachers have to face the reality that nowadays everybody is connected to a worldwide web - let alone teenagers! (Joana, linhas 4-6)

A aluna-professora começa seu exemplo fazendo uso de oração condicional e de uma modalização lógica colocando o que está sendo enunciado como relacionado ao mundo objetivo e das condições prováveis (...when I have my students I can post things in a blog...). Essas marcas indicam uma projeção de Joana como futura professora bem como sua capacidade (ou talvez necessidade em função do lugar social em que está nesse momento) de articular suas experiências enquanto aluna do curso de Letras com sua (futura) prática profissional.

No mesmo excerto, Joana ao justificar o uso do blog pelos professores se implica junto ao grupo profissional por meio do pronome pessoal we e do aposto teachers e faz uso da modalização lógica have to para reforçar a necessidade dos professores encararem as TDIC e usá-las em seu benefício (We teacher have to face the reality that nowadays...). Novamente, o uso de uma modalização atrelada ao mundo social e das obrigatoriedades indicam que Joana, assim como Taylor também verbalizou, tem uma representação construída de que o uso de TDIC é inerente à sociedade em que vivemos.

\section{Considerações Finais}

As análises demonstraram diferentes momentos de (re)constituição identitária das alunas-professoras participantes dessa pesquisa. Nas produções de Taylor, o assumir-se como aluna-professora é geralmente marcado por um conflito de ordem interna, muitas vezes verbalizado. A emergência de tal conflito é marcada pela obrigatoriedade de participar em uma disciplina cujas atividades voltavam-se para o uso de tecnologias digitais e de realizar diversas atividades institucionais requeridas pelo curso de licenciatura no qual se encontra. Os espaços fronteiriços, menos simétricos e de mais autoria permitiram que Taylor, ao produzir postagens em seu blog e refletir sobre essas experiências, se colo- 
casse em confronto consigo mesma e com as coerções sociais que marcam sua formação profissional.

Diferentemente, Joana ressignificou os objetivos almejados pelos professores a partir da intervenção para irem ao encontro de seus interesses pessoais. A aluna-professora, que também se marca pouco enquanto tal, usou o blog profissional para produzir contradiscursos em relação à hegemonia do discurso de formação presente na esfera em que se encontra. Seu engajamento como aluna-professora se dá preferencialmente a partir do relato da prática vivenciada no contexto de estágio do PIBID. Essa característica indica, portanto, que o papel atribuído por Joana a si mesma é condizente com alguém que está e não é professora.

A partir do panorama levantado, acreditamos que assumir enquanto aluna-professora, nos casos de Taylor e Joana, que não desejam seguir essa carreira, foi um processo de confronto possibilitado pelas escolhas das temáticas e das características específicas dos gêneros digitais. Esse papel generativo do blog profissional enquanto uma ação digital de linguagem que problematiza as identidades sociais previamente assumidas se mostra relevante para educação de professores de línguas de forma crítica e reflexiva e parece ser uma alternativa viável para exploração em ações pedagógicas futuras na educação inicial de professores de língua inglesa.

\section{Notas}

1. Initial elementary certification (K-5).

2. Optamos pelo uso do termo alunos-professores para indicar a natureza transitória e de aprendizagem profissional na qual se encontram alunos do curso de Letras-Inglês licenciatura na qual geramos os dados. Outra nomenclatura comum na literatura é professores em formação/pré-serviço e que consideramos equivalente à noção de alunos-professores.

3. Os nomes das participantes são fictícios e foram escolhidos por elas durante a geração de dados.

4. Acreditamos que o formato de estágio no qual Joana está inserida é condição essencial para que esse processo ocorra.

\section{Referências}

ANJOS-SANTOS, L.M. O(s) papel(eis) do gênero digital fórum de discussão educacional na educação inicial de professores de língua inglesa. Acta Scientiarum. Language and Culture. Maringá, v. 36, n.2, p. 159169, abr./jun., 2014.

ANJOS-SANTOS, L.M.; CRISTOVÃO, V.L.L. Práticas de linguagem do meio virtual e a educação inicial de professores de línguas: o gênero textual fórum de discussão educacional. In: CALVO, L.C.S.; EL KADRI,M.S.; ORTENZI, D.I.B.G.; DA SILVA, K.A. (Org.). Reflexões sobre ensino de línguas e formação de professor no Brasil: uma homenagem à professora Telma Gimenez. Campinas, SP: Pontes Editores, 2013, p. $265-289$.

ARAÚJO, J.C. Os chats: uma constelação de gênero na internet. 341p. Tese (Doutorado em Linguística) Universidade Federal do Ceará, Fortaleza, 2006.

ASKEHAVE, I; NIELSEN, A.E. Digital genres: a challenge to traditional genre theory. Information Technology \& People, v. 18, no 2, p. 120-141, 2005.

BRAGA, D.B. Tecnologia e participação social no processo e consumo de bens culturais: novas possibilidades trazidas pelas práticas letradas digitais mediadas pela internet. Trabalhos em Linguística Aplicada, Campinas, v.49, no 2, 2010, p. 373-391.

BRONCKART, J. P. Atividade de linguagem, textos e discursos: por um interacionismo sócio-discursivo. São Paulo: EDUC. Tradução de Anna Rachel Machado e Péricles Cunha, 2003.

COHEN, L.; MANION, L.; MORRISON, K. Research Methods in Education. London: Routledge, 2007.

CRISTOVÃO, V.L.L. Sequências didáticas para o ensino de línguas. In: DIAS, R.; CRISTOVÃO, V.L.L. (Orgs.). O livro didático de língua estrangeira. Campinas: Mercado de Letras, 2009, p.305-344.

HERNÁNDEZ-RAMOS, P. Web logs and online discussions as tools to promote reflective practice. The Journal of Interactive Online Learning, v.3, n.1, p.116, 2004.

KOCH, I.V. A inter-ação pela linguagem. 3a. ed. São Paulo: Contexto, 1997.

LÉVY, P. Cibercultura. Tradução de Carlos Irineu da Costa. São Paulo: Editora 34, 1999, 264p. Tradução de: Cyberculture.

MACHADO, A.R.; BRONCKART, J-P. (Re-)configurações do trabalho do professor construídas nos e pelos textos: a perspectiva metodológica do grupo ALTERLAEL. In: ABREU-TARDELLI, L.S.; CRISTOVÃO, V.L.L. (Org.). Linguagem e Educação: o trabalho 
do professor em uma nova perspectiva. Campinas: Mercado de Letras, p. 31-78, 2009.

MATENCIO, M.L.M. Gêneros Discursivos na Formação de Professores: reflexões sobre a construção de saberes e o processo de letramento. In: GIL, G.; VIEIRAABRAHÃO, M. H. (Org.). Educação de Professores de Línguas: os desafios do formador. Campinas: Pontes Editores, 2008, p.189-199.

MARCUSCHI, L.A. Gêneros textuais emergentes no contexto da tecnologia digital. In: MARCUSCHI, L.A.; XAVIER, A.C. (Org.). Hipertexto e gêneros digitais. Rio de Janeiro: Lucerna, p. 13-90, 2004.

MILLER, C.R.; SHEPHERD, D. Questões da blogosfera para a teoria de gênero. In: DIONÍSIO, A.P.; HOFFNAGEL, J.C. (Org.). Estudos sobre gênero textual, agência e tecnologia. Recife: Editora da UFPE, 2009, p. 93-121.

Blogar como ação social: uma análise do gênero weblog. In: DIONÍSIO, A.P.; HOFFNAGEL, J.C. (Org.). Estudos sobre gênero textual, agência e tecnologia. Recife: Editora da UFPE, 2009, p. 61-92.

PEREIRA, A.C.B.G. Blog, mais um gênero do discurso digital? In: SIMPÓSIO INTERNACIONAL DE ESTUDOS DE GÊNEROS TEXTUAIS, IV, 2007, Tubarão. Anais... Tubarão: Unisul, 2007, p. 516-523. Disponível em: < http://www3.unisul.br/paginas/ ensino/pos/linguagem/cd/Port/9.pdf >. Acesso em: 24/08/2011.

REIS, F.C.S. O e-mail e o blog: interação e possibilidade pedagógicas. In: ARAÚJO, J.C.; DIEB, M. (Org.). Letramentos na Web: gêneros, interação e ensino. Fortaleza: Edições UFC, 2009, p. 99-110.

SANTOS, L.M.A. Panorama das pesquisas sobre TDIC e formação de professores de língua inglesa em LA: um levantamento bibliográfico a partir da base de disssertações/teses da CAPES. Revista Brasileira de Linguística Aplicada. Belo Horizonte, v. 13, n.1, p. 1536, 2013.

WASSELL, B.; CROUCH, C. Fostering connections between multicultural education and technology: incorporating weblogs into preservice teacher education. Journal of Technology and Teacher Education. Chesapeake, VA, v.16, n.2, p.211-232, 2008.

Recebido em: 04/02/2015 Aceito em: 20/03/2015 